\title{
Experiências estético-dialógicas em arte-ativismo
}

Artigo Inédito

Irene de Araujo Machado

(D) 0000-0002-1662-258X

palavras-chave: arte-ativismo; espaço público; interação dialógica; iconicidade; design político.

keywords: Art-Activism; Public Space; Dialogic Interaction; Iconicity; Political Design.

*Universidade de São Paulo (USP), Brasil.

DOI: 10.11606/issn.2178-0447. ars.2019.159755
Aesthetic-Dialogical Experiences in Art-Activism

Experiencias estético-dialógicas en el arte-activismo
Embora frequentemente se entenda arte-ativismo como performances artísticas feitas por coletivos, experiências estéticas individuais, solitárias e silenciosas podem representar gestos de força criativa e contestatória. Ao tomar a arte-ativismo como objeto de estudo, o ensaio discute a potência dialógica de obras que, ocupando o espaço público, alteram as relações do entorno. Explora-se, assim, a dinâmica interativa por meio dos próprios objetos e eventos estéticos que, a partir de seus procedimentos, mostram-se capazes de iconizar tanto o gesto criador do artista quanto seu discurso e ideais mais amplos. Com isso, cria-se uma relação entre arte e política que estimula a exploração plástica do sensório, como se procurou examinar no ensaio.

Although art-activism can frequently be associated to artistic collective performances, solitary and silent individual aesthetic experiences can also represent gestures of creative and contestatory intent. By approaching artactivism as an object of study, this essay discusses the dialogic power of works that occupy the public space, changing the relations established in the environment. In that sense, these interactive dynamics are explored through objects and aesthetic events that symbolize, through artistic procedures, both the artist's creative gesture and his/hers broader discourse and ideals. As a consequence, a relation between art and politics is created, bringing the plastic exploration of the senses to the foreground of the composition, as this essay tried to demonstrate. 
Aunque, por activismo artístico, se entiendan las representaciones artísticas colectivas, las experiencias estéticas individuales, solitarias y silenciosas pueden representar gestos de fuerza creadora y contestativa. Al tomar el arteactivismo como un objeto de estudio, el ensayo analiza el poder dialógico de las obras que, ocupando el espacio público, alteran las relaciones con el entorno. De esta manera, esta dinámica interactiva puede ser entendida a través de los objetos y eventos estéticos que, gracias a sus procedimientos, pasan a simbolizar tanto el gesto creativo del artista como su discurso e ideales más amplios. Con esto, se crea una relación entre la arte y la política que estimula la explotación plástica del sensorio, como se intentó examinar en el ensayo.
46

Irene de Araujo Machado

Experiências

estético-dialógicas

em arte-ativismo

palabras clave:

arte-activismo; espacio publico; interacción dialógica; iconicidad; diseño político. 
1. MESQUITA, A. L. Insurgências poéticas: arte ativista e ação coletiva. São Paulo: Annablume/FAPESP

2011.

2. GROYS, B. Sobre o ativismo artístico. Poiésis, Niterói, v. 18, n. 29,2017, p. 206

\section{Introdução}

A ocupação de ruas e lugares de grande circulação por protestos de caráter político não é prática recente ${ }^{1}$, apesar das ondas de proporções agigantadas, a partir de 2010 e em diferentes partes do mundo, terem feito crer que aquela seja um "fenômeno fundamental de nosso tempo porque é um fenômeno novo" ${ }^{2}$. $\mathrm{Na}$ verdade, o que tais movimentações trouxeram de novo diz respeito à participação de novos agentes de mobilização com o uso dos meios móveis da comunicação eletrônico-digital, bem como das mídias sociais criadas a partir deles. Estes sim mudaram a dinâmica das atuações no mundo. O alcance das ferramentas introduziu novas formas de ação igualmente diversificadas, conferindo aos meios e mídias digitais um protagonismo singular, fundamental para a mudança do caráter da ação política do protesto no cenário urbano, com capacidade de repercussão em larga escala. Tudo isso contribuiu para que os meios móveis fossem definidos como o acontecimento distintivo da comunicação no século XXI. Coube a eles encaminhar desafios à compreensão e redefinição do que se entende por espaço público como espaço comunicacional de interações em campo de confrontos, incluindo limites geopolíticos igualmente abalados pelo novo quadro de atuações.

Os meios móveis de comunicação sem dúvida desempenharam um papel fundamental para a repercussão das mobilizações e para impulsionar mudanças. Contudo, não se pode ignorar que são as atuações, traduzidas em comportamentos e práticas, que constituem os portadores de sentido de todas as intervenções, de seu grau de mobilização e de seu potencial de transformação. Atuações que não se fazem representar por fórmulas consolidadas, mas demandam descobertas, elaborações de novos procedimentos configurados em novas ações.

A partir do momento em que o debate político ocupa o espaço público, é natural que diferentes setores da vida sociocultural também participem, que as atuações se modifiquem e que pontos de vista divergentes se manifestem. Não é de se estranhar, portanto, que as performances artísticas tenham se engajado às mobilizações, 
introduzindo as atividades da arte-ativismo não só no processo de contestação como também no processo de comunicação, no qual diferentes explorações da criação estética entram em ação, partindo de repertórios renovados de formas de interlocução e de reivindicação.

Eis que se colocam algumas indagações: como ler, no procedimento estético, a performance do ativismo? Ou melhor, como distinguir, nas intervenções, o modus operandi de uma poiética geradora de formas estéticas com efeitos potenciais?

Tomando forma nos movimentos e eventos contestatórios a partir dos anos 1960, a noção de arte-ativismo - ou artivismo, como muitos artistas preferem denominar ${ }^{3}$, sem seguir muitas distinções - consolida-se quando passa a designar a arte da cultura digital ativista que se serve das redes informáticas, a net art e o hacktivismo, de modo a disseminar contestações de interesse coletivo, sem hesitar recorrer à desobediência civil como instrumento legítimo de reivindicação. Segundo Laura Baigorri ${ }^{4}$, a designação de intervenções artivistas começa a ser utilizada pelo artista britânico Heath Bunting nos anos de 1980 para designar suas intervenções em rádios e na internet $^{5}$. Já a denominação net art se consagra em meados dos anos 1990 como desígnio da "arte da rede"6.

Ao considerar as diferentes manifestações de arte-ativismo nos espaços públicos das mais distintas ocorrências políticas, um vasto repertório de formas e possibilidades estéticas revela dimensões singulares da própria arena em que os confrontos acontecem. Um inusitado diálogo entre criação estética e espaço se configura como discurso vigoroso de um ativismo bem distinto da dinâmica das agitações que, no início do século XX, abriram caminho para movimentos estéticos como os agit-prop ${ }^{7}$ do construtivismo russo, pesadas as diferenças. Enquanto as atividades agit-prop se realizavam como agenda política em nome da revolução socialista de 1918, as intervenções estéticas atuais, em sua maioria, colocamse no contracampo das forças políticas dominantes, o que acirra os enfrentamentos ${ }^{8}$. Há, ainda, intervenções estéticas que não se confundem com o discurso político das movimentações imediatas do protesto amparado por grandes manifestações e que são performatizadas por grupos e coletivos cuja atividade se realiza em espaços urbanos.
48 Irene de Araujo Machado

Experiências

estético-dialógicas

em arte-ativismo

3. MOURÃO, R. Ensaio de artivismo. Vídeo e performance. Lisboa: Museu do Chiado, 2014a, p. 23 et seq.

4. BAIGORRI, L. Recapitulant: models d'artivisme (19942003). Artnodes. Journal on Art, Science and Technology, v.1, 2003. Disponível em: <https://artnodes.uoc.edu/ articles/abstract/10.7238/a. v0i3.692/pdf $>$. Acesso em: 29 de janeiro de 2019 .

5. Em entrevista a James Flint publicada na revista Wired 50. Cf. FLINT, J. O., Be owned or remain invisible. Wired, 50 , s/d. Disponível em: <https:// www.irational.org/_readme. $\mathrm{html}>$. Acesso em: $31 \mathrm{de}$ janeiro de 2019.

6. Ver CARRILO, J. Arte en la red. Madrid: Cátedra, 2004; GONÇALVES, F. N. Arte, ativismo e tecnologias de comunicação nas práticas políticas contemporâneas. Contemporânea, Rio de Janeiro, v.10, n.2, 2012, p.178193. Disponível em: <http:// www.contemporanea.uerj.br/ pdf $>$. Acesso em: 23 de janeiro de 2019; TRIBE, M.; JANA, R. Arte y Nuevas Tecnologías. Köln: Taschen, 2006. 
Mesmo tendo florescido como performance de arte urbana, convém lembrar os de intervenção que resultam da gestualidade de

7. Agit-prop: designação das atividades de agitação produzidas por poetas, artistas do teatro, cinema e artes de rua no sentido de promover a atração como forma estética, ou seja, a ação e reação das pessoas em espetáculos, concertos, eventos de arte. 0 procedimento foi explorado por Maiakóvski em sua poesia e cartazes de propaganda (janelas ROSTA) e também por Sergei Eisenstein em suas montagens teatrais do Proletcult. Nelas, o futuro cineasta já trabalhava com as atrações montando a sucessão de episódios por meio de conflitos e incorporando acontecimentos da atualidade sob forma de sketch. Como manifestação estética do Construtivismo, os agit-prop vinculavam arte à propaganda política da NEP (Nova Política

Econômica, programa implantado por Lênin, em 1921, que recuperava algumas práticas capitalistas de modo a incrementar a recémimplementada economia soviética).

8. GROYS, B. Arte, poder. Belo Horizonte: Editora UFMG, 2015, p. $16 ; 229$

9. Diálogo interno velado emerge como procedimento poético na criação artística do escritor russo Fiódor

Dostoiévski. Trata-se de uma forma discursiva que se desenrola entre a vocalidade e o silêncio pleno, de embates que se interiorizam e travam um só corpo ou uma só voz, revelando a plenivalência de um discurso que se sustenta pela singularidade e potência de seu processo criativo. E eis que somos surpreendidos por manifestações de arteativismo de outra qualidade estética: aquela que nasce diretamente da relação com o entorno e com ele cria uma voz, travando um diálogo nem sempre convergente e muitas vezes até dissonante, ruidoso e com muitas refrações - mananciais vigorosos da poiesis artivista.

Com isso, vemos florescer uma gama de intervenções políticas que faz das formas estéticas o meio de expressão no espaço público. Algumas visam a mobilizações coletivas em larga escala; outras, a intervenções pontuais e solitárias. Grande parte delas se caracteriza não só pela presença do artista, com a consequente exploração de seu próprio corpo, como também por obras e procedimentos criadores do gesto artístico que não se limita ao corpo e aos traços da composição, mas que se serve do entorno enquanto constituinte, criador de relações construtivas integradas à organicidade da interação. Quando o próprio signo estético se oferece como interação no espaço público, formas inusitadas de diálogo emergem. Traços marcantes de composições dessa natureza valorizam o silêncio, a imobilidade, o quase anonimato, a quase invisibilidade, a quase incomunicabilidade que define tão bem o discurso interno velado ${ }^{9}$ dos grandes embates polêmicos - o que poderia levantar a suspeita de um ativismo às avessas. Tais são os traços que inserem no ativismo agentes bem distintos do que aquilo que, historicamente, entende-se por sua artéria política fundamental: multidões em espaços abertos a entoar palavras de ordem ou gritos de guerra. Distintos porque sua natureza se define tão somente pela capacidade de traduzir para a linguagem da arte elementos cujo caráter não é necessariamente estético.

Em linhas gerais, o raciocínio esboçado aqui introduz o objeto de estudo do presente ensaio. Interessa-nos examinar o processo de tradução de demandas sócio-políticas em procedimentos estéticos que, ao serem incorporados aos espaços de convivência, travam com eles diferentes diálogos, alguns bastante imediatos e previsíveis, outros completamente imprevisíveis. Espera-se, se não responder à 
pergunta, pelo menos indagar e examiná-la: como ações imediatas são convertidas esteticamente em ideias, ideais, lutas?

Na primeira parte do ensaio, examina-se o trabalho de arteativismo como categoria analítica, de modo a situar a construção crítica de procedimentos que funcionem como agentes tradutores de propostas ativistas abertas ao diálogo com seu entorno. Seguese, então, a análise de procedimentos explosivos que deslocam campos de sentidos e abrem espaço para relações e configurações imprevisíveis, de modo a interagir com essas novas circunstâncias, produzindo estranhamento. Finalmente, são investigadas as criações em que elementos do próprio entorno se convertem em procedimentos composicionais, de modo a ampliar a prática performática, incorporando diferentes formas de metalinguagem. $\mathrm{Na}$ conclusão, este artigo se propõe a enfrentar o eixo do fundamento teórico orientado pelo tenso debate sobre a relação entre arte e política.

\section{Arte-ativismo como categoria analítica}

O objeto de estudo do presente ensaio não focaliza apenas as performances de arte-ativismo do ponto de vista de sua construção estética, ou do inventário de seus efeitos. O foco se volta para o diálogo que a intervenção estabelece com o seu entorno e para a poiesis estabelecida nessa articulação. Trata-se, portanto, da interação entre objeto estético e o evento dialógico entendido como um conjunto de experiências para o qual convergem as noções de "ideia", "ideal" e "luta", que se pretendem transformadoras, cada uma a seu modo. Somente nesse sentido é possível entender a força e o papel da intervenção em seu caráter estético-artístico e político, sem que um se confunda com o outro. São as experiências de arte-ativismo realizadas dentro dessa necessidade que definem o objeto de estudo do ensaio e, portanto, são elas que fornecem a linha especulativa de todo o raciocínio apresentado, bem como a metodologia de análise.

Na tentativa de compreender os processos de tradução plástica de ideais e da luta em experiência estético-dialógica, e a consequente
50

Irene de Araujo Machado

Experiências

estético-dialógicas

em arte-ativismo

com interlocutores empíricos ou imaginários dissensos de grande força argumentativa e de contestação. Exame minucioso desse processo criativo foi desenvolvido por $M$. M. Bakhtin. Ver BAKHTIN, M. M. Problemas da poética de Dostoiévski. Rio de Janeiro: Forense Universitária, 2008. 
10. As duas exposições citadas são aquela realizada

na galeria da artista no parque-museu de Inhotim, em Brumadinho, MG, visitado

em janeiro de 2018, e a mostra Claudia Andujar: A luta Yanomami, no Instituto Moreira Salles, São Paulo, SP, em 2018 e 2019.

Figura 1: Claudia Andujar, A luta Yanomami. Instituto Moreira Sales, São Paulo, 2019. FONTE: tomada in loco em 29 de janeiro de transformação desses elementos em agentes de interlocução no espaço sócio-cultural e político, uma das experiências a ser lembrada como marco encontra-se na obra fotográfica de Claudia Andujar com comunidades indígenas da Amazônia, visitada em dois espaços expositivos distintos ${ }^{10}$. No exame das fotos, vídeos, dos textos curatoriais e críticos em cada uma dessas ocasiões, foi possível apreender caminhos de um processo de tradução plástica de ideias, ideais e da própria luta política em que a fotografia, colocada a serviço de uma causa - no caso, a demarcação das terras dos índios Yanomami -, investe-se de diferentes funções, deslocando os campos significantes de seu entorno.

Sabemos que desde os anos de 1970 a artista se engajou no ativismo conduzindo seu trabalho documentário e experimental como modo de pensar as ações políticas. Dentre os vários trabalhos produzidos nessa época, bem como as várias experiências testadas pela artista, atende aos interesses de nossa investigação o uso da fotomontagem como forma de interlocução argumentativa à disputa pela terra questão. Trata-se do trabalho [Fig. 1] em que o uso da fotomontagem traduz o procedimento da composição plástica encarregado da interlocução argumentativa na disputa pela terra em questão. É como argumento que o experimento de linguagem realiza um discurso cujas ideias atravessaram o tempo e o espaço.

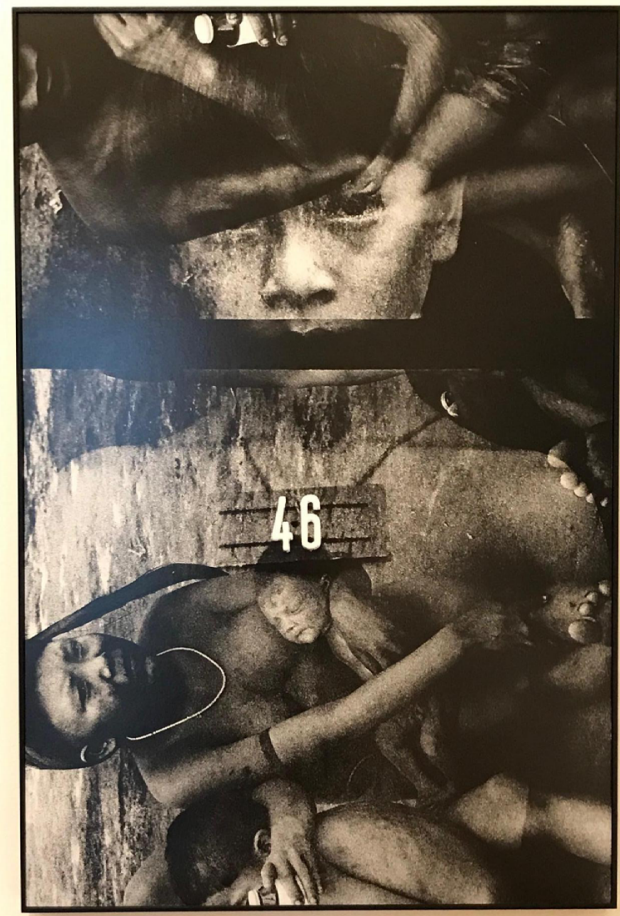


Andujar se engajara na frente de luta pela demarcação quando, em 1975, pesquisas aéreas descobriram a existência de minérios nobres em toda a região ocupada pelos indígenas, ao norte do país. Diante da afluência de garimpeiros e mineradores no local, não apenas comunidades indígenas foram dizimadas como também a própria área em que a artista havia montado seu ateliê foi destruída e desativada. Na luta pela demarcação, havia que se comprovar não o pertencimento, mas a própria existência das pessoas nas comunidades. A foto reproduzida aqui é apenas uma de um imenso arquivo de registros identitários dos índios. Seu destaque deve-se ao fato dela ter consagrado um experimento de intervenção que incide tanto sobre o processo fotográfico quanto sobre o ambiente sóciopolítico e cultural do país.

Um primeiro ângulo de observação da fotografia revela a existência dos indígenas pela sobreposição dos corpos nus. Estes, posicionados ao longo da superfície da obra, encontram-se contorcidos e em diferentes ângulos de atravessamento: uns sobre os outros, partes de uns que surgem de outros e se transformam. Mãos e braços se tocam, ainda que as poucas bocas e olhos permaneçam fechados. Todos estão inseridos em uma unidade orgânica em relação ao único tronco tomado em ângulo frontal, cujos lábios aparecem cobertos por uma faixa preta.

A fotografia em questão é significativa não apenas como documento de identificação das pessoas que vivem nas áreas alvo da demarcação, embora tal fato corresponda à intenção inicial da artista. A gestualidade dos corpos enuncia muitos discursos, com reconhecida força argumentativa na própria topografia da composição, em que estão implicados ideias e ideais de luta pela voz, pelo direito de desfrute da terra, pelo reconhecimento da ancestralidade, enfim, pelo respeito à história e pelo direito à demarcação da terra - que aconteceria apenas em 1992. Torna-se impossível refutar a noção de que o vigor argumentativo da montagem emana dos diferentes ângulos de visão a partir dos quais os corpos foram tomados e da qualidade estética do conjunto. No trabalho, que vincula argumento a composição estética, de modo que ambos se impliquem mutuamente, os distintos planos enunciativos abrem diálogo para um campo muito maior de interlocução, ampliando seu circuito e alcançando a vida sócio-política. E aqui se situa o eixo 

como a voz onipresente da floresta, sempre alerta às novas ameaças que não cessam.

Um trabalho de arte-ativismo dessa natureza é emblemático pela sua proposta e também pelo caminho que abre para pensar o ativismo como categoria analítica, que experimenta suas possibilidades discursivas e argumentativas em virtude da causa defendida. Consequentemente, ele suplantaria os próprios termos da definição de ativismo, centralizados na "ocupação" e no "espaço aberto" "1. A obra mostra-se, assim, muito mais disposta a não incorrer nos riscos que poderiam advir desse tipo de ação, contestados por

11. GIOVANNI, J. R. di. Artes de abrir espaço. Apontamentos para a análise de práticas em trânsito entre arte e ativismo. Cadernos de Arte e Antropologia, Salvador, v.4, n.2, p.13-27, 2015. Disponivel em: <https:// journals.openedition.org/ cadernosaa/911?file $=1 . \mathrm{pdf}$. Acesso em: 29 de jan. 2019.

12. BENJAMIN, W. Le cinéma russe et l'art collectiviste. Cahiers du Cinéma, 1971, pp.

226-7.

13. Argumentatio ad hominen: estratégia discursiva de natureza falaciosa que não apenas é destituída de formulações analíticas imprescindíveis ao argumento como também dele se desvia, resvalando para embates e ataques pessoais, uma vez que não enxerga nada além de ocorrências dispersas.

14. BENJAMIN, W. Para uma crítica da Nova Objetividade (1930-31). Linguagem, Tradução, Literatura. Filosofia, teoria e crítica. Porto: Assírio \& Alvim, 2015, pp. 136-7. ninguém menos que Walter Benjamin, que, diante do imediatismo de todo ato utilitário, acabou por negar o uso da arte como mera extensão da política. Estava lançada uma semente para se pensar arte-ativismo como categoria crítico-analítica dimensionada pela plasticidade do conjunto de experiências estéticas mobilizadas.

O mesmo Walter Benjamin que enfrentou o debate da obra de arte construída no contexto de sua reprodutibilidade técnica situando a poiesis de seus procedimentos na sua condição enquanto agente da transformação dialética dos estados de consciência, motivada, sobretudo, pela experiência do cinema ${ }^{12}$ - declarou a impossibilidade da relação entre arte e política. Orientado por argumentos de irrefutável fundamentação, entendeu que a arte, ao assumir interesses alheios à sua constituição plástica, anulava sua possibilidade de reflexão, passando a excluir a discussão, a se insurgir contra a teoria, a recorrer unicamente aos fatos, a combater a ficção e, o que é mais grave, a limitar qualquer debate tão somente à argumentatio ad hominen ${ }^{13}$. Segundo ele,

\footnotetext{
Nunca como hoje, uma geração de jovens escritores mostrou tanto desinteresse pela legitimação teórica do seu prestígio. Tudo que vá para além de uma argumentatio ad hominen já está fora dos seus horizontes. Como poderia ela chegar a um esclarecimento teórico das suas posições se essas estão voltadas para dentro e excluem em si mesma todo e qualquer ponto de vista mais lúcido? ${ }^{14}$
} 
E, no epílogo de seu consagrado texto "A obra de arte na era da reprodutibilidade técnica”, a visão de tal impossibilidade é agudizada ao proclamar que, enquanto o fascismo introduziu a estetização da vida política, coube ao comunismo politizar a $\operatorname{arte}^{15}$. Estetização da política e politização da arte, segundo seu entendimento, não só selaram a impossibilidade de qualquer relação construtiva e lúcida entre arte e política como também condenaram a arte ao servilismo de agendas políticas momentâneas, tais como os interesses do mercado.

Nesse sentido, uma alternativa para tal embate emerge em intervenções ativistas que não temem experimentações, transgressões, estranhamentos, imprevisibilidades e, sobretudo, metalinguagem crítica de seus próprios procedimentos, sem personalismos e atuações coletivas em grande escala. Será que Andujar imaginara que os registros identitários de sua luta iriam ressoar como presença ativa no século 21 ?

Como categoria analítica, arte-ativismo não deixa de ser considerada em seu engajamento com a contestação, nem exclui de seu horizonte a pretensão de intervir e, consequentemente, mudar a ordem das coisas. Contudo, como se pretende evidenciar, seu modus operandi pode ser definido pelo caráter experimental dos procedimentos composicionais empregados nas intervenções, assentados no circuito que vincula "ideia", "ideal" e "luta". Talvez a hipótese arriscada de nosso estudo seja propor tal tríade como possibilidade para enfrentar o desafio proposto por Walter Benjamin ao colocar em xeque o vínculo entre arte e política e questionar a utilidade e o servilismo da arte articulada a finalidades políticas. Afinal, diferentes processos artísticos não deixam de investigar novos modos de interagir com o mundo e formas dialógicas impensáveis, mananciais de linguagem sem os quais nenhuma cultura sobrevive.

\section{Ação escultórica em experiências estéticas explosivas}

Se, por um lado, a categoria crítico-analítica dos procedimentos estéticos pode ser entendida em sua dialogia interativa e, portanto, integrada ao seu contexto histórico, por outro, trata-se de dimensionar
54

Irene de Araujo Machado

Experiências

estético-dialógicas

em arte-ativismo

15. BENJAMIN, W. A obra de arte na era da sua reprodutibilidade técnica. Sobre arte, técnica, linguagem e política. Lisboa: Relógio d’Água, 1992, p. 112. 

abrissem caminho para a imprevisibilidade, deixando vir à tona a explosão necessária para o surgimento do devir e da inovação. Tais intervenções de arte-ativismo desafiam um certo estado de coisas com transgressão e irreverência, evidenciando experiências estéticas explosivas.

Antes de continuar, há que se esclarecer a natureza semiótica do conceito de explosão, cuja base filosófica em nada lembra o princípio físico de combustão. Enquanto princípio filosófico, a explosão não deriva da dinâmica que envolve ação e reação, ou estímulo e resposta, mas de transformações encadeadas no âmbito de uma gradação. É nesse sentido que o semioticista russo Iúri Lótman concebe o processo de mudanças culturais explosivas, como fica claro no segmento que se segue:

A humanidade tem vivido, entre os séculos XVIII e XX, um processo que pode ser descrito como a realização de uma metáfora: os processos socioculturais se encontram sob o influxo da imagem de explosão, não como conceito filosófico, mas sim em sua correlação vulgar com a explosão da pólvora, da dinâmica do núcleo atômico. A explosão como fenômeno físico, transferível somente por metáforas a outros processos, tem sido identificada pelo homem contemporâneo com ideias de devastação e se tornou símbolo de destruição. Porém, se na base de nossas representações atuais estivessem associações com as épocas dos grandes descobrimentos, como o Renascimento, então o conceito de explosão evocaria fenômenos como o nascimento de uma nova criatura viva ou qualquer outra transformação criativa da estrutura da vida. ${ }^{16}$

16. LOTMAN, Y. M. Cultura y explosión. Lo previsible y lo imprevisible en los procesos de cambio social. Barcelona: Gedisa, 1999, pp. 22-3. Tradução minha.
Em sua investigação sobre o movimento da história no interior de processos graduais marcados pela previsibilidade - como o que a ciência empreende ao atender a necessidades da tecnologia -, o autor observa que a criação e as descobertas, tanto na ciência quanto na arte e na vida, emergem em circunstâncias de total imprevisibilidade. Desarranjos ocasionados por toda sorte de intercorrências acontecem à revelia do circuito de causa e efeito, desequilibrando um estado de ordenamento e instalando incertezas sem previsão de novos rumos. Esse é o momento de explosão que, ao instalar a crise no sistema, 
56

vislumbra um novo equilíbrio, acompanhado por novas descobertas e pela livre criação ${ }^{17}$.

Na mesma linha da imprevisibilidade e da incerteza, situamse intervenções de arte-ativismo baseadas em confrontos, choques, paradoxos, que produzem a desestabilização e o estranhamento, de modo a deixar o espaço criativo livre e aberto a formas e pensamentos inovadores. $\mathrm{Ou}$, como formulara Benjamin, deixar emergir "novas regiões de consciência”. Nada é previsível, uma vez que a cadeia causal não é alimentada de modo a produzir imediatismos.

O trabalho da artista brasileira Néle Azevedo se situa nesse contexto. Em Monumento mínimo, de 2013, uma de suas instalações escultóricas [Fig. 2], o gesto de imprevisibilidade realiza-se por meio da efemeridade da obra. Um gesto performático inusitado apreende a transitoriedade do corpo sem, contudo, servir-se dele ou intervir diretamente sobre ele. Com não mais de vinte centímetros de comprimento, as esculturas miniaturais construídas por Azevedo em gelo mostram figuras humanas sentadas, que são distribuídas pela artista por escadarias de lugares públicos nas diferentes cidades em que a artista já performatizou sua obra. De monumental, só a legião de formas humanas que se desfaze minutos após a montagem.

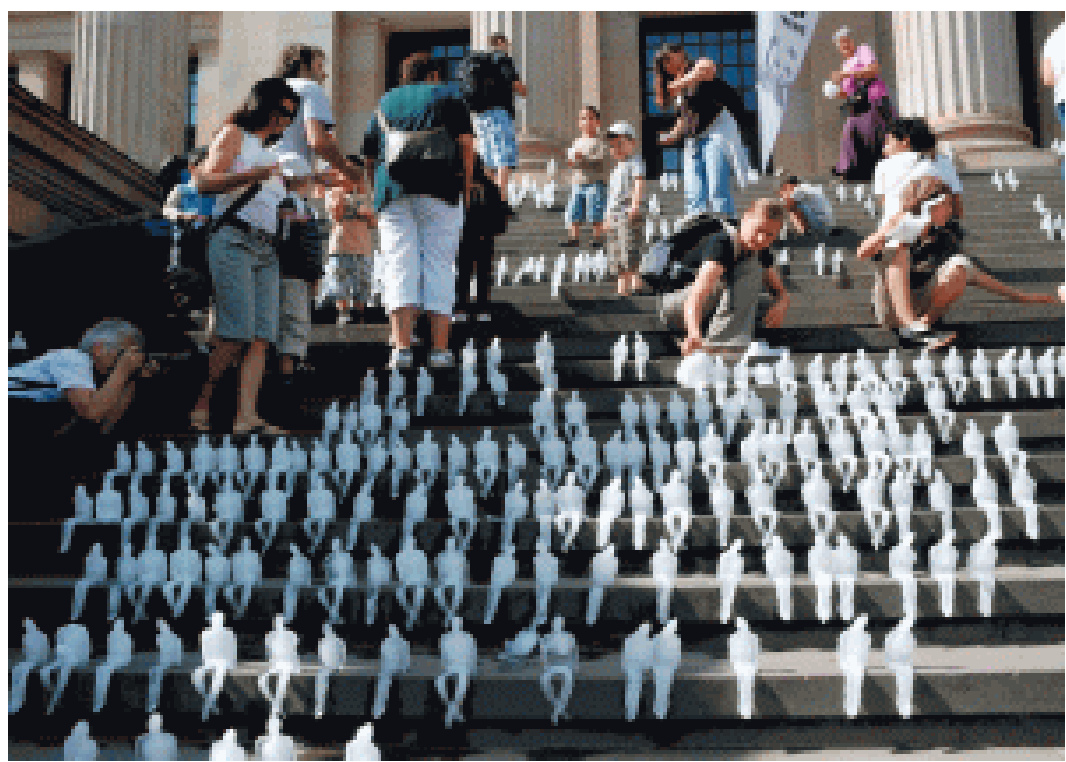

Irene de Araujo Machado

Experiências

estético-dialógicas

em arte-ativismo

17. LOTMAN, Y. M. The Unpredictable Workings of Culture. Tallinn: Tallinn University Press, 2013, p.64 et. seq.

Figura 2: Néle Azevedo, Monumento mínimo, 2013. Memorial da América Latina, São Paulo. FOTOGRAFIA: Silvina Der Meguerditchian. FONTE: https://artenalinha. wordpress.com/2013/02/19/ nele-azevedo-apresentamonumento-minimo-nomemorial/ 
Em uma mise en scène na qual o espaço público e seus

18. "Montagem por conflito" no sentido em que Sergei Eisenstein praticou não apenas no cinema conceitual como também na construção de cenários e atuações teatrais, na qual o conflito se torna agente de mudança em um curso supostamente previsível de acontecimentos, deslocando sentidos para zonas inesperadas.

19. TONELLI, L. Arte e espaço

urbano. Entrevista online com Néle Azevedo. Disponível em: <https://www.goethe.de/ ins/br/pt/kul/mag/20968261. $\mathrm{html}$ ?forceDesktop=1>. Acesso em: 24 de janeiro de transeuntes são os agentes vivos da interação, as imagens corpóreas e voláteis exploram a radicalidade de uma "montagem por conflito" 18 e desencadeiam um tenso diálogo com os visitantes e o entorno em que a obra se instala.

Enquanto concebia o Monumento mínimo, o contexto de embates de Azevedo gravitava em torno dos monumentos institucionais, de estátuas e esculturas cravadas em espaços públicos para louvar os bravos comandantes e generais de guerras. Em poses e gestos de proporções e volumes agigantados, o conflito bélico é cristalizado em momentos gloriosos. Tudo construído em grande escala, para que não restem dúvidas sobre o poderio e a força das instituições que essas imagens representam. Monumento mínimo reconstrói o dilema que o instante de glória abriga e que os monumentos ocultam: o momento da guerra em que a glória emerge de vidas que se oferecem como sacrifício. Vida e Morte, dilema tão bem semiotizado desde o próprio título da instalação, em que o signo de qualidade (mínimo) nega sua referência (monumento) e, ao fazêlo, expressa um desvio que conduz à negação do que se mostra.

Tudo no espaço da intervenção reproduz confrontos: as escalas entre seres humanos, edifícios, esculturas; a solidez e longevidade das construções e a efemeridade e transitoriedade das esculturas de gelo; a vulnerabilidade do monumento mínimo, deixando exposto todo o minimalismo de sua constituição; guerra e paz; glória e derrota; vida e morte. No entendimento da artista, a principal característica de Monumento mínimo é ser

[...] um antimonumento, subvertendo uma a uma as características dos monumentos oficiais. No lugar da escala grandiosa, largamente utilizada como ostentação de grandeza e poder, propus uma escala mínima. No lugar do rosto do herói da história oficial, uma homenagem ao observador anônimo, ao transeunte, numa espécie de celebração da vida, do reconhecimento do trágico, do heroico que há em cada trajetória humana. E no lugar de materiais duradouros, propus as esculturas em gelo, que duram cerca de trinta minutos. Elas não cristalizam a memória, nem separam a morte da vida, mas ganham fluidez, movimento e resgatam uma função original do monumento: lembrar que morremos. ${ }^{19}$ 
A potência de negatividade do signo na relação com seu objeto é sem dúvida suficiente para colocá-lo em uma posição de choque e confronto com as possibilidades interativas e comunicacionais. Se o diálogo demanda continuidade, a fim de firmar o elo em um circuito de interações, nada poderia ser mais antidialógico do que uma performance artística baseada na diluição do próprio objeto de criação, gesto em que se explicita a transitoriedade e fugacidade do espaço e do tempo. Não obstante, deve-se atentar para a iconicidade que a performance constrói a partir da fugacidade, da transitoriedade e da finitude do objeto, que dialogam, por outro ângulo, com a trajetória humana e a própria vida - como entende a artista. Iconicidade que não traduz apenas o "ser" do signo, mas o "pode ser" e o "vir a ser" da existência. Uma possibilidade de pensamento inusitado que se apresenta como manifestação plasticamente explosiva da ideia em trânsito, nascida dos espaços de realização da performance. Afinal, as esculturas de gelo serão líquido a escorrer em um curto espaço de tempo, deixando no ar ideias em gestação.

Quando as pessoas interagem com a legião de homens minúsculos de gelo derretendo e virando água, é muito difícil lembrar que a obra surgiu como homenagem aos combatentes de guerra. $\mathrm{Na}$ verdade, é mais comum contextualizá-la na pauta contemporânea do derretimento das geleiras causado pelo aquecimento global, o que leva o trabalho a ser tratado como produção estética de ativismo ambiental. Monumento mínimo antecedeu a exposição "Exemplos a seguir! Expedições em Estética e Sustentabilidade”, na qual a obra foi exibida ${ }^{20}$. O objetivo da mostra era estabelecer relações entre arte, ciência e sustentabilidade, contando com a participação de artistas nacionais e internacionais que, desde o ano de 2010, cumprem sua jornada sobre sustentabilidade percorrendo cidades do mundo e submetendo seus trabalhos a diversas temperaturas climáticas, o que promove a variação de seu potencial dialógico no espaço expositivo. A artista não contava com essa dimensão ativista com a qual a obra passou a interagir, nem com a situação imprevisível em que a mesma é tomada como interrogação sobre a condição dos espaços de convívio, entendidos como ambientes de coexistência sem os quais a própria vida se torna ameaçada. Como uma obra tão efêmera pode cogitar um diálogo com a preservação da vida, uma dimensão de tal magnitude? Eis a explosão dialética entre signos do
20. Galeria Marta Traba, Memorial da América Latina, São Paulo, 2013. 
minimalismo, do monumental, da magnanimidade.

O desvio para outra dimensão de sentido não torna a obra

21. No horizonte de nossas análises estão também as obras Presenças liquidas

(2015) e a recentíssima Estado de suspensão, performada em 28 de junho de 2019 nas escadarias do Teatro Municipal de São Paulo, em uma ação em que as figuras de gelo, então reproduzidas no tamanho natural do corpo humano, foram suspensas por fios de nylon, com iluminação especial e música acompanhando a liquidificação das formas.

22. "A pólis não era Atenas, e sim os atenienses". Ver ARENDT, H. A condição humana. Lisboa: Relógio d’Água, 2001, p. 245 apud MOURÃO, R. Op. cit. 2014a, p.

41, n. 12

23. VIRILIO, P. 0 espaço crítico. São Paulo: Editora 34, 1993, p. 22 et seq.

24. 0 conceito da metaperformance nos remete ao processo de produção interpretativa no qual a obra performática não apenas se realiza como uma única interpretação, mas se também a outras possibilidades de leitura, constituindo, assim, a cadeia aberta de interpretantes. Ver CONQUERGOOD, D. Poetics,

Play, Process, and Power:

The Performative Turn in Anthropology. Text and

Performance Quarterly, 1989 9 (1): 82-95; MOURÃO, R. 0 Carnaval é um palco, a ilha imediatista ou mero exemplar de estetização política, uma vez que é o diálogo com o entorno que transporta o sentido para esferas não cogitadas. Assim, as esculturas se multiplicam, replicando corpos em movimentos e intervenções sempre imprevistas ${ }^{21}$.

Longe de ser apenas uma forma de contestação, o espaço dialógico da arte-ativismo assim constituído valoriza a alteridade do convívio, recuperando uma dimensão do espaço público cuja historicidade merece, igualmente, ser reposicionada sempre que possível. Trata-se da concepção de espaço público que floresceu na pólis grega, em cuja ágora primava-se pela livre manifestação de pessoas e discursos, preservando sua condição fundamental como lugar de convívio, de interação, de comunicação entre os cidadãos. Lembrando Hannah Arendt ${ }^{22}$, se o espaço público deixa de ser dos cidadãos, então ele é privado da dimensão política garantida pela pólis. Em última análise, fica comprometido o impulso vital da experiência estética, em sua capacidade de transição do sentido para outras regiões de consciência. Perdem-se, consequentemente, os vínculos entre pólis, política e percepção, tal como formulados por Paul Virilio ${ }^{23}$.

Quando as intervenções de arte-ativismo recuperam tais vínculos, a performance transforma os gestos da própria experiência estética em procedimento fundamental de sua poiesis, tornada, assim, metaperformance ${ }^{24}$. Pouco importa que a materialidade sólida de seu objeto derreta e escorra como um líquido qualquer. Ainda que Néle de Azevedo, como muitos artistas de sua geração, reverencie Zygmunt Bauman, filósofo que proclamou as "relações líquidas" de nosso tempo, não custa lembrar que a máxima "tudo que é sólido desmancha no ar" foi proclamada por Karl Marx e Friedrich Engels. "Lançado em uma garrafa" para percorrer os tempos, o enunciado buscava não deixar morrer o questionamento e até mesmo a indagação de que "nem tudo que é sólido desmancha no ar", como contra-argumentou o poeta ${ }^{25}$. 


\section{Estranhamento do corpo dialógico em espaços residuais estilhaçados 26}

A noção de que "nem tudo se desmancha no ar", segundo o raciocínio do filósofo Paulo Arantes, constitui-se como um contradiscurso à máxima do Manifesto Comunista (1948) em seus argumentos mais fundos: a concepção de que "mecanismos de reprodução social em que a iniciativa cabe apenas à inovação econômica define justamente a pré-história da humanidade” ${ }^{27}$. A passagem da pré-história em que se vive sob o domínio do capital e do mercado será acompanhada pela emancipação estrutural das sociedades. Todavia, em vez de diluição do capitalismo, como faz crer a máxima do Manifesto, Arantes, em seu contra-argumento, entende que nem tudo se desmancha no ar, uma vez que a exploração se exaure à medida que forças produtivas de suas próprias contradições começam a emergir sob a "forma invisível de poderes subterrâneos e incontroláveis” ${ }^{28}$. Esse raciocínio será o introito de um outro que lhe foi contemporâneo, e que julgamos ter alcançado o momento explosivo da cultura do século XXI.

$\mathrm{Na}$ virada do século, um olhar atento mostra que, após a acomodação do pós-guerra e o ulterior aprimoramento da exploração segundo a lógica do mercado, um dique devastador se rompeu e, explosivamente, deixou-nos sem rumos ou definições. Nem o sólido nem o desmanche, apenas caminhamos por entre estilhaços. Este olhar, encarregado de apreender a metáfora do estilhaço, emana do raciocínio do antropólogo Clifford Geertz. Em pleno devir do novo milênio, Geertz surpreende ao divisar um dos dilemas que iriam assumir perspectivas cada vez mais conflituosas e alarmantes logo nas primeiras décadas do século XXI: a desarticulação dos povos em torno das linhas geopolíticas dos Estados-nação. Ao refletir sobre a impossibilidade de uma teoria política de caráter geral em um mundo em que blocos antagônicos, potências compactas e arranjos de macroalianças foram desmontados, deixando à mostra seus pedaços desarticulados, Geertz argumenta que "os grandes conceitos integradores e totalizantes que por tanto tempo nos acostumaram a usar para organizar nossas ideias" também haviam se desintegrado. O que nos leva a inferir que, "num mundo estilhaçado", só nos resta "examinar os estilhaços" ${ }^{29}$. No longo ensaio, sustentando uma
60

Irene de Araujo Machado

Experiências

estético-dialógicas

em arte-ativismo

uma festa: da performance

cultural à exposição da

sua metaperformance

videográfica. MIDAS. Museus

e Estudos Interdisciplinares.

Lisboa, n.3, pp.1-18, 2014b.

PDF. Disponível em: <https://

journals.openedition.org/

midas $/ 582$ ? lang $=p t>$. Acesso

em: 16 de junho de 2019;

TURNER, V. The Antropology

of Performance. New York:

PAJ Publications, 1986.

25. Paulo Arantes cita o conto homônimo do escritor brasileiro Jorge Miguel Marinho, no qual a sentença aparece reformulada, e que serviu de mote ao seu artigo. Ver ARANTES, P. Nem tudo que é sólido desmancha no ar. Estudos Avançados, São

Paulo, v. 12, n. 34, pp. 100-103, 1998. Disponível em: <http:// www.scielo.br/pdf/ea/v12n34/ v12n34a17.pdf>. Acesso em: 28 de janeiro de 2019.

26. Qualificamos como residual os espaços subtraídos das construções urbanas, designando aquilo que resta (escombros e ruínas) e tudo o que sobra e não interessa à especulação imobiliária, como becos, encostas, barrancos e os lugares precários destinados à construção de moradias.

27. ARANTES, Paulo.. Op. cit., p. 102.

28. ARANTES, Paulo. Idem.

29. GEERTZ, C. 0 mundo em 

em voga, o antropólogo indaga: "que é um país, se não é uma nação? [...] que é uma cultura, se não é um consenso?"30.

A noção de mundo estilhaçado de Geertz abre caminho para movimentações subterrâneas que podem levar a novos

pedaços: cultura e política no fim do século. Nova luz sobre a antropologia. Rio de Janeiro: Zahar, 2001, pp. 192-3.

30. GEERTZ, Ibidem, p. 196.

Figura 3: Bansky, Soldier throwing flowers, 2005, Palestina. FONTE: <https:// www.culturagenial.com/ obras-banksy/>. Acesso em: 15 de dezembro de 2018. direcionamentos, particularmente à reorganização do pensamento $\mathrm{e}$ das práticas de conduta, o que favorece a emergência de atividades de renovação e criação em que intervenções de arte-ativismo se coloquem no contrafluxo e mergulhem nos estilhaços do sistema. Intervenções em espaços públicos fragmentados por confrontos e guerras de grupos étnicos, de caráter político ou religioso, tornaramse espaços residuais de criação e de produção de objetos estéticos. Quando os artistas transformam escombros e estilhaços em signos de um corpo dialógico, os resíduos tornam-se potencialmente criadores de códigos, deixando flagrantes, nos procedimentos estéticos que foram desenvolvidas nessas arenas específicas de conflito, as contradições e paradoxos instauradas nesses espaços.

Um dos trabalhos que já produziu não apenas muitas intervenções nessa esfera como também se tornou emblemático nessa modalidade de arte-ativismo foi produzido pelo artista britânico Bansky, em suas projeções em muros e paredes da faixa de Gaza nos primeiros anos do século XXI. Recorrendo ao estêncil como forma de reprodução, o artista aplica seus moldes de acetatos, que são preenchidos a tinta, nas superfícies de paredes e escombros - um trabalho, portanto, cuja produção nasce declaradamente sob o signo do design. Recursos que, evidentemente, não seriam capazes de imprimir nenhuma singularidade ao trabalho estético, não fosse o diálogo que o figurativismo estabelece com o entorno em que a obra foi instalada, como se pode verificar na reprodução abaixo [Fig. 3].

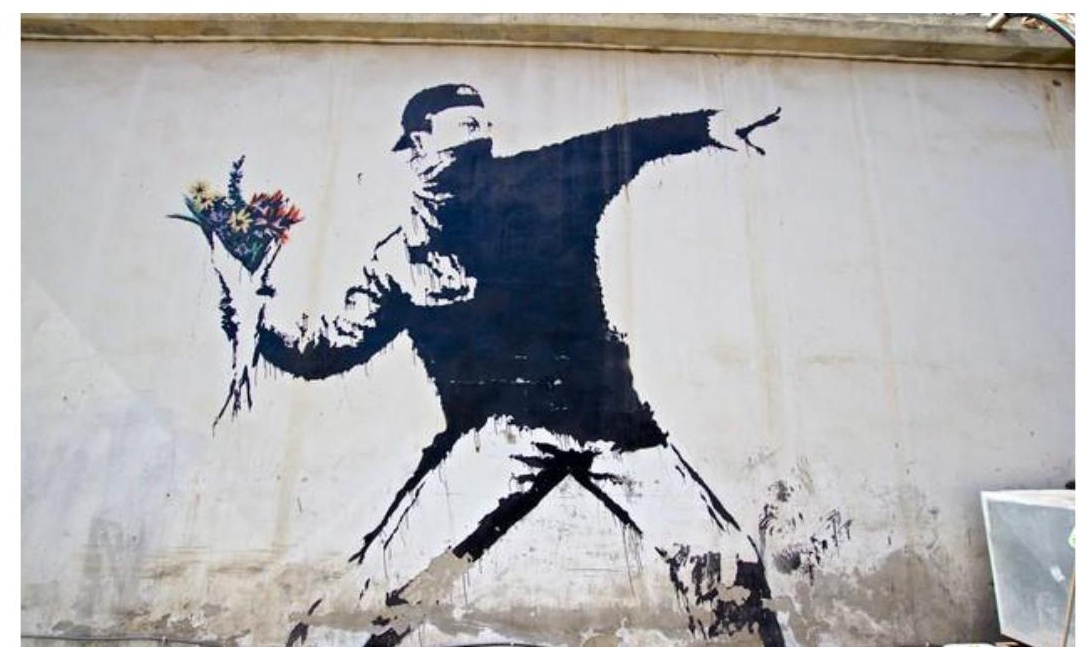


Na ação impressa no desenho, concentra-se toda a carga 62 Irene de Araujo Machado dialógica da composição. Por meio de uma trama de estranhamentos, os gestos se deslocam do espaço de representação para o espaço de convívio e nele buscam interação com os supostos observadores. Do extracampo onde foi inscrito, observam-se as relações invertidas e transgressoras: flores no lugar de arma, arremesso no lugar de oferta, força no lugar de um abraço, reação transgressora no lugar de um gesto encerrado em si mesmo. Nesse campo, emergem relações dialógicas imprevisíveis como espaço de performance, no sentido pleno da palavra, apontando para a gestualidade transgressora que revira pelo avesso a imagem cristalizada. Aquilo que parecia sólido se desfaz e insinua outra possibilidade, ainda que hipotética, mas completamente consoante com a construção de metalinguagens críticas, que tomam a si mesmas como objeto de reflexão. Um exemplo preciso do deslocamento dos sujeitos discursivos, que elide a presença do artista e embaralha o jogo enunciativo.

$\mathrm{O}$ momento fugidio de um gesto transgressor pode sintetizar o caráter da performance, que estabelece diálogos situados na esfera das ideias. Para um artista que se consagrou com base no anonimato, esse tipo de intervenção de arte-ativismo, que prescinde da presença do artista, revela o quanto as obras podem ser portadoras de seu próprio discurso. Tal é o campo de sentido que vemos impulsionar trabalhos projetados em lugares de risco e de difícil acesso [Figs 4 e 5].

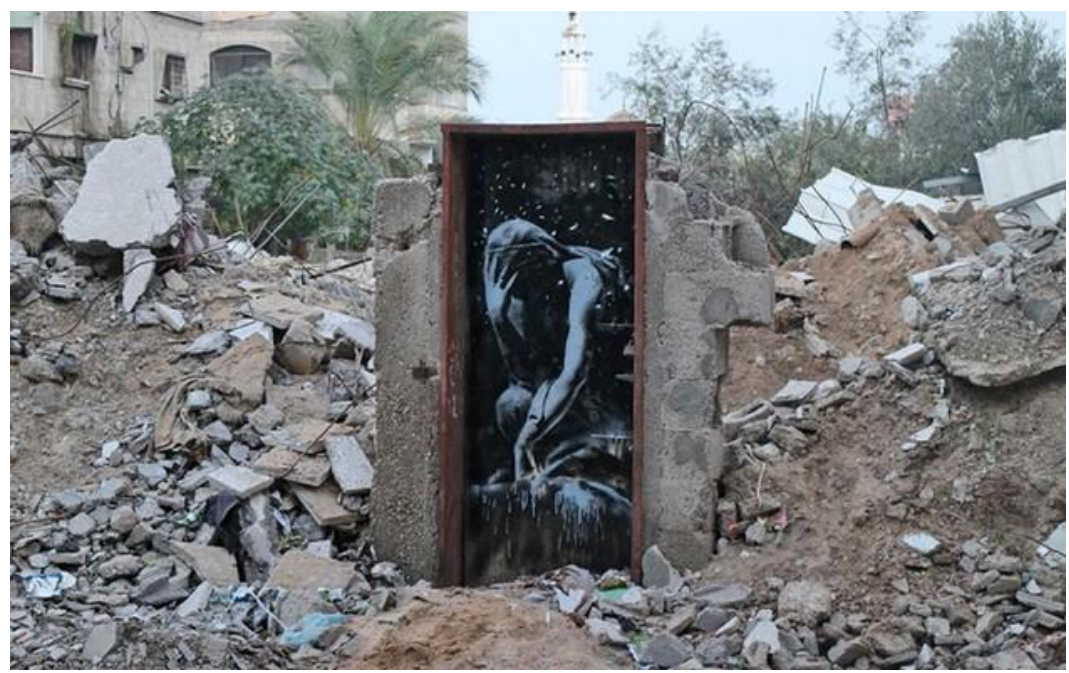

estético-dialógicas

em arte-ativismo 
33. A foto do menino que olha o muro já foi objeto de análise em outro artigo.

Cf. MACHADO, Irene.

Tensionamento dos espaços de fronteira: conceitos como obstruções epistemológicas. Revista Latinoamericana de Ciencias de la Comunicación, v. 15, n. 28(2018), pp. 97-99.

Figuras 8 e 9: Pejac (Silvestre Santiago), Arte de rua: Pinturas invertidas. Assentamento palestino Al-Hussein, em Amman, Jordânia, 2016. Disponível em: $<$ http://art-tension.tumblr. com/post/143985964665>. Acesso em: 20 maio 2018. vivenciais, entabulando conversas imaginárias com as pessoas que por eles transitam [Figs. 6 e 7]. Enquanto a reportagem traduzia o ativismo dessa arte minimalista como denúncia do confinamento, da precariedade das habitações e da opressão, um exame do processo criativo realizado diretamente nos escombros revela algo bem mais relevante.

O trabalho (artístico e fotográfico) de Pejac chegou ao nosso conhecimento por meio de reportagens foto-jornalísticas tanto em meio impresso como em formato eletrônico-digital ${ }^{33}$.

Ao ser focalizada pela câmera do fotógrafo, a composição artística foi ambientada em um arranjo cênico em que os moradores não apenas se deslocam como também interagem com as gravações nos muros, muitas vezes desviando o primeiro plano para si. Nas fotos reproduzidas acima, tal movimento é conferido às figuras da mulher e do menino, que assumem o protagonismo da cena. A mise em scène, assim organizada, além de se colocar pronta para ser tomada pelas lentes da câmera, condiciona e direciona os olhares que para ela se dirigem. No primeiro plano da tomada em perspectiva, situa os transeuntes; no ponto de fuga, o desenho. Coube à fotografia jornalística compor a montagem interna das fotos publicadas, de modo que as gravações dos muros e paredes fossem lidas a partir de tal construção perspectiva. Com isso, a montagem fotográfica do cenário evoca todo um mundo interior dotado de um diálogo interno que, embora velado e aparentemente sem voz, passa a ser apreendido pelo imaginário de observadores externos. Apesar do silêncio e do jogo de invisibilidade, existem índices evidentes de uma suposta trama vivencial que une, por contrastes, os observadores diretos da cena e as gravações minimalistas por eles fitadas, tal como reproduzido a seguir [Figs. 8 e 9].
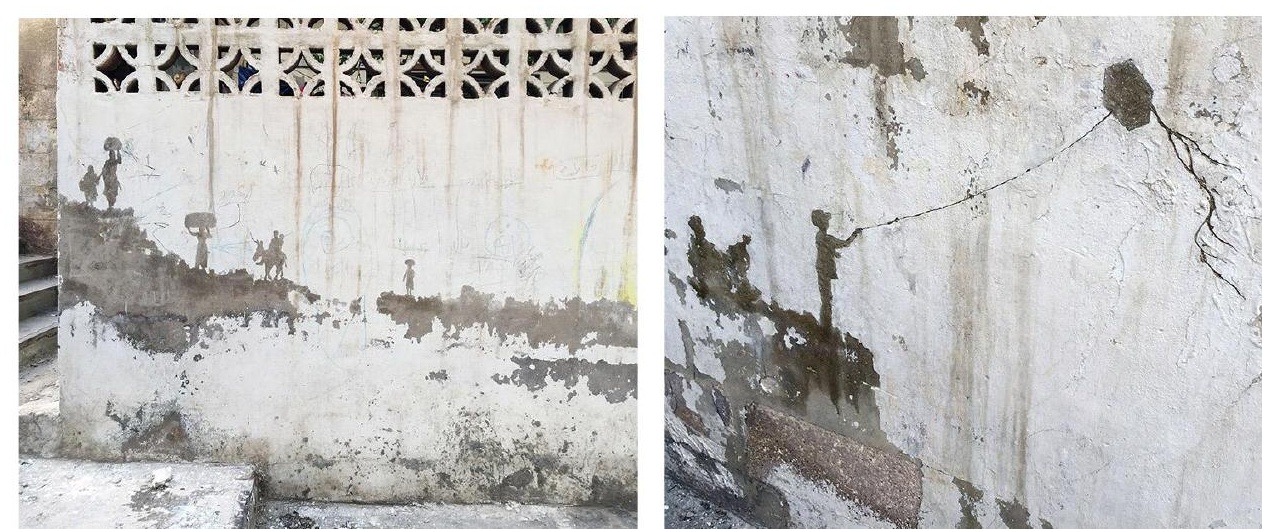
Se a motivação dessas imagens negativas - ou pinturas invertidas - era gravar episódios de uma história, nos desenhos, por sua vez, são recuperadas vivências de lugares e memórias de tempos de trabalho e de lazer, ou mesmo cenas prosaicas do deslocamento em um terreno acidentado, permeado por obstáculos a serem transpostos. Podem ser cenas vivenciadas pela mulher que olha o mural ou por seus antepassados.

Em ambos os casos, a superfície do muro se abre para outros espaços e tempos, e a densidade do concreto armado se torna uma superfície transparente e porosa a projetar lugares imaginários possíveis. As gravações acabam reproduzindo diversas visibilidades sem esconder planos de invisibilidade, reveladas a percepções atentas ao ambiente político que o espaço configura. Tudo isso pode ser observado olhando as figuras que são gravadas a partir dos códigos gráficos que compõem os escombros. Contudo, com a reprodução foto-jornalística, é desencadeado outro olhar, outra esfera dialógica e um imaginário de caráter especulativo do qual emergem uma mise en scène distinta, organizada em torno de noções que buscam traduzir situações como errância, privação, opressão, violência e intolerância sob outros pontos de vista ou, simplesmente, com outro sentido. E esse é outro tipo de ativismo, que é afastado da pura denúncia ou do protesto que se apaga depois da performance em função do seu caráter conceitual.

Estamos diante de uma experiência estética de metaperformance que se realiza criticamente na análise das gravações murais em que a própria construção dos desenhos intervém nas ranhuras e rasuras das paredes; em que as marcas da destruição são recuperadas pelo traço gráfico e ganham novos contornos pela ação do cinzel. Ela não deixa de reproduzir desenhos com suas formas, mas não se confunde com o grafite nem com a arte mural. Destes e dos afrescos, porém, herda a possibilidade de operar nas fronteiras entre o interior e o exterior, o visível e o invisível. Contudo, o resultado não é uma escultura e sim uma gravação em que o estilete é cravado em contornos de escombros. E, tal como os palimpsestos, ela sobrepõe aos sulcos disformes de rachaduras, estilhaços e entalhes de concreto os contornos gráficos de formas de eventos vivenciais transformados em imaginário.

Além de produzir códigos gráficos com materiais que
66 Irene de Araujo Machado

Experiências

estético-dialógicas

em arte-ativismo 
supostamente não são próprios para isso, o artista estimula percepções em que o próprio olhar do sujeito traduz os objetos e eventos estéticos observados de modo igualmente performativo e imprevisível. Do gesto artístico solitário, marcado por ausências e lacunas, emergem orientações muito mais abertas às atuações do imaginário, sem antecipar nenhum efeito de sentido conclusivo. No caso dos desenhos de Pejac sobre as paredes do assentamento palestino, a reportagem afirmou que se tratava de recuperar uma história de luta. Contudo, a própria edição das imagens nas fotos abre espaço para que o olhar elabore suas próprias formulações, tal como os olhares depositados nas gravações. A partir do momento em que o próprio ato de ver entra na composição do quadro fotográfico, é impossível ignorar a emergência de um discurso velado em voga naquele espaço. A mulher de costas para a câmera e o menino em tomada perpendicular evocam discursos não ditos, embora existentes, a problematizar qualquer afirmação conclusiva, fortalecendo o caráter metaperformativo da composição.

Discurso interno velado é uma formulação que Mikhail M. Bakhtin concebeu a partir da análise da poética dialógica da obra

34. BAKHTIN, M. Mikhail. Op. cit., p. 270 et seq

35. BAKHTIN, M. Mikhail. Ibidem, p. 233. de Dostoiévski ${ }^{34}$. A noção reporta-se a toda enunciação evasiva em que o não dito de vozes silentes, embora não vocalizadas, reverbera nos espaços de interação, fazendo circular ideias, contrapontos, polêmicas e até mesmo contradiscursos. Ela se desdobra de um espaço exterior para um espaço mental interior, o que permite antecipar reações - tal como se operou na reportagem sobre as gravações de Pejac no muro, em que a cena fotográfica antecipa, para o leitor-observador, a motivação do artista na produção das imagens murais. Contudo, como se trata de um discurso não dito, a evasiva também abre espaço para outras formulações e, em vez de ser a "última palavra", ela se revela apenas um "ponto condicional, não um ponto final" ${ }^{35}$, o que confere inacabamento, se não à composição estética, pelo menos ao campo dialógico que lhe serviu de habitat formativo.

Como diálogo inconcluso, o procedimento suscita a formação de uma cadeia enunciativa que nunca chega à palavra final, mas introduz diferentes possibilidades interpretativas e dialógicas. Graças à sua capacidade de desdobramento, o procedimento, em suas diferentes explorações, encaminha-se em direção a reproduções 
convergentes e divergentes. Com isso, o artista elabora esteticamente o gesto e o desenho que executa, estetizando até mesmo o olhar, de modo a leva-lo a alcançar aquilo que não é da ordem do visível, mas que reverbera em outros espaços.

Na fronteira entre o visível e o invisível, situam-se formas que pensam e jamais se limitam ao imediatismo das atuações que levaram Benjamin a cindir a relação entre arte e política. Se fronteira é, sobretudo, um espaço semiótico de confrontos, de imprevisibilidade, conforme o entendimento de Lótman, o que se infere dessas análises é que as intervenções de arte-ativismo não podem configurar atuações sólidas que se desmanchem no ar, mas construções diagramáticas, capazes de vincular as mais complexas esferas da ação política a procedimentos construtivos da própria arte. Não sem motivo, as metaperformances se desdobram por entre espaços fronteiriços e se encaminham para traçados imprevisíveis.

\section{Encaminhando conclusões com alguns enfrentamentos} necessários

Iniciamos nosso caminho analítico da arte-ativismo seguindo a alternativa que não se orienta nem pela estetização da política, sustentada pelo espetáculo de grandes mobilizações no espaço público aberto, nem pela politização da arte, com performances concebidas como porta-vozes de agendas sociais salvacionistas. Para isso, foi fundamental a metodologia de exame de intervenções artísticas concentradas nos procedimentos composicionais que procuram traduzir, nos efeitos estéticos, as ideias e os ideais da luta política. Criando, assim, interações dialógicas capazes de subsidiar a emergência de reflexões e sentidos imprevisíveis, acreditamos que essas práticas possam conduzir a "novas regiões de consciência". Consideramos a dialogia esteticamente construída a partir de procedimentos tais como estranhamento, explosividade, montagem, discurso velado, mise en scène, metaperformances. Desse modo, entendemos a arte-ativismo como categoria analítica crítica.

Evidentemente, a investigação foi conduzida segundo o caráter hipotético da proposta argumentativa do ensaio com relação ao desafio proposto por Walter Benjamin, que sustenta a impossibilidade da relação entre arte e política. Reconhecemos,
68 Irene de Araujo Machado

Experiências

estético-dialógicas

em arte-ativismo 

argumento a abordagens como as do crítico Boris Groys.

36. GROYS, Boris. Sobre o ativismo artístico. Poiésis. Niterói, v.18, n. 29, 2017, p.
Como epígono, com certa representatividade, no conjunto da crítica de arte vinculada ao pensamento de Benjamin, Groys se empenhou em rever o conceito de estetização no âmbito de uma certa produção crítico-criativa contemporânea que, graças à dependência dos meios tecnológicos e das estratégias de mercado, aproximou-se da noção de espetacularização de Guy Debord. Assim posicionado, entendeu a relação entre arte e ativismo como orientada por princípios perversos, uma vez que a estetização da política opera com desvios dos objetivos políticos e os transforma em procedimentos estéticos que simplesmente escamoteiam seus reais propósitos. A transformação da ação política em espetáculo de mero entretenimento acabaria neutralizando o foco essencial do protesto $^{36}$.

O debate de Groys merece atenção especial, ainda que não toque diretamente na questão que nos interessa, sobretudo por se concentrar fundamentalmente na compreensão de duas concepções de estetização que contribuem para o debate das contradições envolvidas na relação entre arte e ativismo. Uma delas decorre da noção de arte como livre criação; a outra, contrariamente, aproxima-se do que hoje se pratica como design, ou seja, o trabalho técnico baseado em ferramentas específicas. No caso das obras que tomam conta do espaço público urbano com grafites, murais, painéis ou displays de grande porte, torna-se imprescindível recorrer às ferramentas tecnológicas e à reprodução técnica - caso dos moldes de Azevedo, dos estênceis de Bansky e, em certo sentido, das fotomontagens de Andujar, ainda que elas não se baseiem em moldes. Com isso, para Groys, trata-se de trabalhos moldados pelo design que mais se aproximam da tradição da ars techné, aplicada tanto à construção de objetos quanto à política, em sentido geral.

Desse modo, a criação profissional de imagens orienta o que o autor entende por design político, cujos exemplos seminais são as grandes mobilizações políticas do nazismo e do fascismo, condenados por Benjamin. Groys, no entanto, pondera que o ativismo artístico atual não pode prescindir do design político, que atualiza tanto a estetização quanto o espetáculo, como se pode ler em sua exposição: 
O ativismo artístico contemporâneo é o herdeiro dessas duas tradições contraditórias de estetização; ele politiza a arte, usa a arte como design político - como uma ferramenta nas lutas políticas de nosso tempo. Este uso é completamente legítimo e criticá-lo seria absurdo. Design é parte integrante da nossa cultura e não faria sentido proibir seu uso por movimentos políticos de oposição com o pretexto de que esse uso leva à espetacularização, à teatralização do protesto político ${ }^{37}$.

Ainda que a formulação de Groys seja fundamentada em argumentos defensáveis e coerentes, sua conclusão não é suficientemente forte para refutar Benjamin, sobretudo porque, ao submeter o design político ao espetáculo e à estetização, parece que o pêndulo de sua avaliação tende para uma posição conciliatória, escamoteada sob a capa de um movimento de suas contradições internas. Não obstante, acontecimentos históricos que assombraram o século XX evidenciaram que as especulações de Benjamin estavam longe de ser argumentatio ad hominem. Espetáculos grandiosos se mostraram construídos pelo mesmo denominador comum, agora travestido pelo viés do mercado e do design político.

Ao examinar as relações entre arte e ativismo do ponto de vista das mudanças que a primeira produziu nas formas de reivindicação das movimentações contestatórias, a antropóloga brasileira Julia R. Don Giovanni é mais enfática em afirmar os benefícios que os movimentos sociais assimilaram a partir de seu contato com as artes:
70

Irene de Araujo Machado

Experiências

estético-dialógicas

em arte-ativismo

37. GROYS, Boris. Op. cit., p. 214.
Longe de representar uma "estetização" do fazer político em que as formas do poder mudariam de "roupagem" ou "estilo", permanecendo, no entanto, estruturalmente iguais a si mesmas, as formas de mobilização sensorial, perceptiva e subjetiva produzidas no seio de processos de rearticulação de lutas sociais estão diretamente implicadas nos deslocamentos da própria política, na expansão de seus significados, quando não em uma radical ruptura com os modos de fazer que anteriormente a separavam do conjunto da ação social considerado não-político - em que a arte, por exemplo, tenderia a situar-se. Do mesmo modo, a implicação de uma prática de origem "artística" em um movimento vivo de organização política e ação coletiva força deslocamentos importantes no campo da arte, desafiando os limites do possível também em termos do que é artístico e do que não é..$^{38}$ 
Ora, as formas de mobilização sensorial, perceptiva e ano 17 subjetiva emanam basicamente da criação e dos espaços abertos, n. 37 não necessariamente no contexto topográfico da vida pública, mas em espaços de confronto dialógico em que o imaginário tem voz e vez.

As obras analisadas, ainda que vinculadas a pautas políticas específicas, imediatas ou não, orientam-se para um outro caminho analítico. Sob o signo da interação e do diálogo, até mesmos espaços de confronto como os escombros de guerra movimentam o campo de forças perceptuais de diferentes matizes sensoriais, propiciando a abertura para a ação do imaginário, em que as interações experimentam outros modos de sensibilidade. Pouco importa que isso se realize por meio de mise en scène, traduções intersemióticas, intervenções nos códigos e linguagens, comuns às metaperformances. O fato é que os artefatos mediadores jogam luz sobre uma segunda natureza da vida sensorial: aquela que somente os meios permitem perceber, apreender, enfim, sentir. 
ARANTES, P. Nem tudo que é sólido desmancha no ar. Estudos Avançados, São Paulo, v. 12, n. 34, pp. 100-103, 1998. Disponível em: [http:/www.scielo.br/pdf/ea/v12n34/v12n34a17.pdf]. Acesso Irene de Araujo Machado

Experiências estético-dialógicas em arte-ativismo em: 28 de janeiro de 2019 .

ARENDT, H. A condição humana. Lisboa: Relógio d’Água, 2001.

BAKHTIN, M. M. Problemas da poética de Dostoiévski. Rio de Janeiro: Forense Universitária, 2008.

BAIGORRI, L. Recapitulant: models d'artivisme (19942003). Artnodes. Journal on Art, Science and Technology, v.1，2003. Disponível em: <https://artnodes.uoc.edu/articles/ abstract/10.7238/a.v0i3.692/pdf $>$. Acesso em: 29 de janeiro de 2019.

BENJAMIN, W. Le cinéma russe et l'art collectiviste. Cahiers du Cinéma, 1971.

BENJAMIN, W. Para uma crítica da Nova Objetividade (1930-31). Linguagem, Tradução, Literatura. Filosofia, teoria e crítica. Porto: Assírio \& Alvim, 2015.

BENJAMIN, W. A obra de arte na era da sua reprodutibilidade técnica. Sobre arte, técnica, linguagem e política. Lisboa: Relógio d'Água, 1992.

CARRIlo, J. Arte en la red. Madrid: Cátedra, 2004.

CONQUERGOOD, D. Poetics, Play, Process, and Power: The Performative Turn in Anthropology. Text and Performance Quarterly, 1989, 9 (1): 82-95;

DON GIOVANNI, Julia R.. Artes de abrir espaço. Apontamentos para a análise de práticas em trânsito entre arte e ativismo. Cadernos de Arte e Antropologia, Salvador, v.4, n.2, p.13-27, 2015. 
GEERTZ, C. O mundo em pedaços: cultura e política no fim do ano 17 século. Nova luz sobre a antropologia. Rio de Janeiro: Zahar, 2001 .

FLINT, J. O., Be owned or remain invisible. Wired, 50, s/d. Disponível em: <https://www.irational.org/_readme.html>. Acesso em: 31 de janeiro de 2019.

GONÇALVES, F. N. Arte, ativismo e tecnologias de comunicação nas práticas políticas contemporâneas. Contemporânea, Rio de Janeiro, v.10, n.2, 2012, p.178-193. Disponível em: <http://www. contemporanea.uerj.br/pdf $>$. Acesso em: 23 de janeiro de 2019.

GROYS, B. Arte, poder. Belo Horizonte: Editora UFMG, 2015

GROYS, B. Sobre o ativismo artístico. Poiésis, Niterói, v. 18, n. 29, 2017.

LOTMAN, Yuri M. Cultura y explosión. Lo previsible y lo imprevisible en los procesos de cambio social. Barcelona: Gedisa, 1999.

LOTMAN, Yuri M. The Unpredictable Workings of Culture. Tallinn: Tallinn University Press, 2013.

MACHADO, Irene. Tensionamento dos espaços defronteira: conceitos como obstruções epistemológicas. Revista Latinoamericana de Ciencias de la Comunicación, v. 15, n. 28(2018), pp. 95-108. Disponível em: <https://www.alaic.org/revista/index.php/alaic/issue/ view/32>. Acesso em: 02 de dezembro de 2019

MESQUITA, A. L. Insurgências poéticas: arte ativista e ação coletiva. São Paulo: Annablume/FAPESP, 2011.

MOURÃO, R. Ensaio de artivismo. Vídeo e performance. Lisboa: Museu do Chiado, 2014a. 
MOURÃO, R. O Carnaval é um palco, a ilha uma festa: da performance cultural à exposição da sua metaperformance videográfica. MIDAS. Museus e Estudos Interdisciplinares. Lisboa, n.3, pp.118, 2014b. PDF. Disponível em: <https://journals.openedition.org/ midas/582?lang=pt $>$. Acesso em: 16 de junho de 2019

TONELLI, L. Arte e espaço urbano. Entrevista online com Néle Azevedo. Disponível em: <https://www.goethe.de/ins/br/pt/kul/ mag/20968261.html?forceDesktop=1>. Acesso em: 24 de janeiro de 2019 .

TRIBE, M.; JANA, R. Arte y Nuevas Tecnologías. Köln: Taschen, 2006.

TURneR, V. The Antropology of Performance. New York: PAJ Publications, 1986.

VIRILIO, P. O espaço crítico. São Paulo: Editora 34, 1993.

Irene de Araujo Machado é Livre Docente em Ciências da Comunicação pela Universidade de São Paulo, Escola de Comunicacõos e Artes. É Pesquisadora de Produtividade em Pesquisa (PQ 1D) e Professora de Semiótica da Comunicação na Cultura, dedicando-se aos estudos dos meios audiovisuais: semiótica do cinema, tradução intersemiótica e estudos do dialogismo. Atua no PPG em Meios e Processos Audiovisuais da USP, onde orienta pesquisas de mestrado, doutorado e pósdoutorado. Publicou livros no campo da semiótica russa, com destaque para: Analogia do dissimilar: Bakhtin e o formalismo russo (Perspectiva, 1989); O romance e a voz: a prosaica dialógica de M.Bakhtin (Imago, 1995); Escola de semiótica: a experiência de Tartu-Moscou para os estudos da cultura (Ateliê-Editorial, 2005).
Irene de Araujo Machado

Experiências

estético-dialógicas

em arte-ativismo
Artigo recebido em 6 de julho de 2019 e aceito em 15 de novembro de 2019. 